\title{
Cathodoluminescence (CL) Microscopy Application to Refractories and Slags
}

\author{
Musa Karakus and Robert E. Moore \\ University of Missouri-Rolla \\ Department of Ceramic Engineering \\ Rolla, MO 65401
}

E-mail:karakus@umr.edu

\begin{abstract}
Refractories are ceramic materials possessing high thermal shock properties and slag corrosion resistance, as well as creep resistance at high temperatures. They are used in large quantities in steel making furnaces, metal smelting vessels, and glass melting tanks, and are made from very refractory minerals such as lime, periclase, corundum, spinel, and zirconia. Slags are residual vitreous materials generated during steel refining processes. They cover a wide range of compositions and may contain pure oxides, silicates, and sulfides as well as fluoride phases, depending on the melting and smelting processes. These minerals exhibit spectacular cathodoluminescence color when bombarded with electrons. Cathodoluminescence (CL) microscopy, therefore, is a very effective technique for the characterization of refractory corrosion by slags. Studies in this paper include: (1) reaction of fluorine containing mold slags with $\mathrm{ZrO}_{2}-\mathrm{C}$ nozzle refractories, promoting crystallization of cuspidine $\left[\mathrm{Ca}_{4} \mathrm{Si}_{2} \mathrm{O}_{7}(\mathrm{~F}, \mathrm{OH})_{2}\right],(2)$ corrosion of fusion cast refractories and formation of glass defects in TV panel glassmaking furnaces, and (3) densification of spinel-based castable in steel melting induction furnace.
\end{abstract}

\section{HISTORICAL OVERVIEW}

\section{History and Definition of Refractories}

The word "refractory" refers to high-melting temperature materials and is known to be derived from the Latin word refractarius, which means stubborn [1]. Refractories are traditionally defined as "non-metallic and shaped ceramic materials that withstand high temperatures". Today, the definition of "refractories" has evolved and extends to practically "any material which can function in a high-temperature environment", as described by Lee and Rainforth [2]. Non-oxide ceramics such as $\mathrm{Si}_{3} \mathrm{~N}_{4}, \mathrm{SiC}$, or anti-oxidant metals added to $\mathrm{MgO}-\mathrm{C}$ composites are, therefore, considered refractories. Irrespective of composition or form, refractories possess one or more of the following properties:

- High refractoriness: durable at temperatures $>800^{\circ} \mathrm{C}$ (fire-proof materials for homes are not classified as refractories)

- Compatible thermal properties: conductivity and expansion

- Good mechanical properties: moduli of elasticity, strength, fracture strength, toughness

- Low thermal shock

- High resistance: abrasion and erosion

- Corrosion resistance to slags, alkalis, metals, chloride solutions, corrosive gaseous species. 
There is, unfortunately, no single refractory material that fulfills all these requirements. Platinum containers offer some of these properties, but they are very expensive. Specialized defectfree glasses used in flat panel displays and optical lens manufacturing, are cast from Pt containers, however. Dense carbon blocks have excellent thermal conductivity and refractoriness, but cannot tolerate oxidation. They are used in the bottom of the melt in blast furnaces and in other nonoxidizing locations.

Today, refractories are fabricated in two forms: shaped refractories and unshaped (monolithic) refractories. Shaped refractories are fired and/or unfired bricks with finite shapes and fusion cast refractories. Monolithic refractories include castables, plastics, gunning, and ramming mixes.

Table I. Refractory Products by Material

\begin{tabular}{|l}
\hline Clay Refractories \\
- Fireclay \\
- High Alumina \\
- Insulating \\
\hline Non-clay Refractories \\
- Alumina \\
- Magnesia \\
- Spinel \\
- Magnesia-chrome \\
- Zircon and Zirconia \\
- Mullite \\
- Silica \\
- Sraphite and Carbon \\
- Oticon Carbide and Silicon Nitride \\
\hline
\end{tabular}

Table II. Refractory Products by Industry

\section{Metal Industry}

- Iron and Steel making

- Coke Oven

- Blast Furnace

- Basic Oxygen Furnace Vessel

- Electric Arc Furnace

- Ladle

- Degasser

- Tundish

- Continuous Caster

- Non-ferrous Metals (Cu, $\mathrm{Zn}, \mathrm{Pb}$, etc.)

- Metal Casting

Ceramic, Glass and Cement Industry

- Ceramic Firing Industry 
- Glassmaking Industry

- Cement and Lime Industry

\section{Petrochemical Industry}

- Petroleum Refining Industry

- Chemical Industry

General refractories types and classifications are given in detail in the Refractories Handbook [3]. Table I shows refractory products by material. Refractories, as described by Lee and Moore [1], are enabling materials that are used for the production of other industrial products. They are, for example, used in steel making and iron-making furnaces, non-ferrous metal smelting vessels, glassmelting tanks, cement kiln furnaces, and petrochemical plants. Table II shows the refractory products by industry.

Total refractories production in United States in 1998 was 3.66 million metric tons [4] with a value of $\$ 2.379$ billion (Figure 1). Refractory sales are expected to reach $\$ 2.8$ billion by 2003 . About $70 \%$ of productions are consumed in the iron and steel making industry followed by cement, ceramic and glass industry. These figures demonstrate that not only significant amounts of refractories are produced and consumed, but that the refractories industry is a major contributor to the US economy when compared to other ceramic industries.

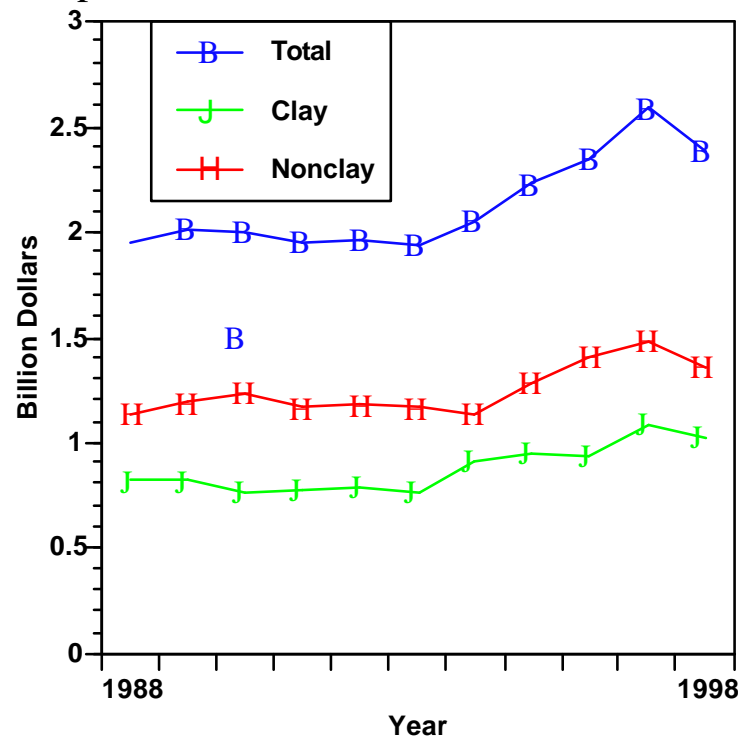

Figure 1. Value of Shipment of Refractories in USA (Source: US Census Bureau, March 2000). 


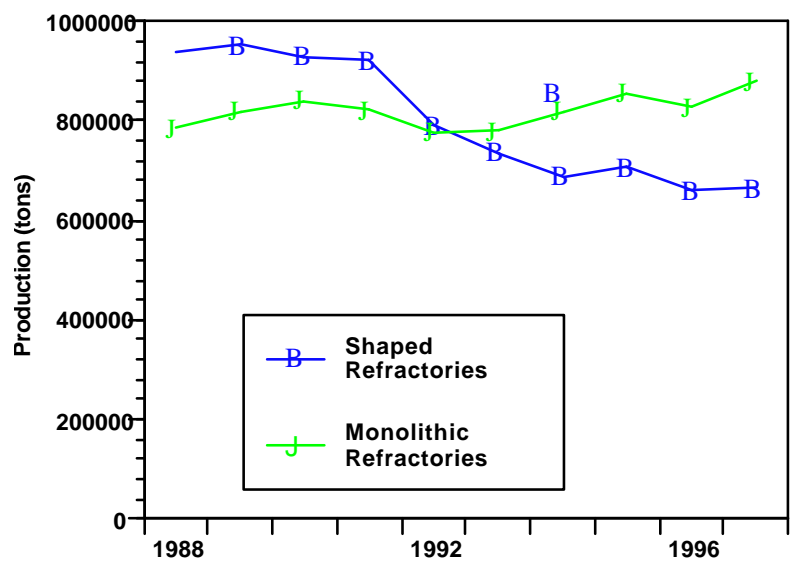

Figure 2. Production of refractories in Japan

Innovative refractory product development is driven mainly by the process development in steel refining for clean steel production and also by environmental regulations, especially in North America. Magnesia-chromite refractories, for example, are still the choice of materials in copper production furnaces and cement kilns around the world. Mag-chrome refractories are also commonly used in regenerator units of fiberglass melting plants and in vacuum degassers. Chromite is indeed an excellent refractory but it has been shown to produce hazardous $\mathrm{Cr}^{6+}$. There is an increasing tendency in the US for chromium-containing refractories to be replaced by spinel-based castables. Another example of environmentally driven change is the recent technology transfer in glass melting plants. About $20 \%$ of the glass plants in the US have already changed their air-fueled firing technology to oxy-fueled firing technology [5]. This reduces the energy consumption (regenerators are no longer required) and allows cleaner glass manufacturing and, most importantly, it eliminates $\mathrm{NO}_{\mathrm{x}}$ emission. Oxy-fueled firing technology, in turn, has introduced new problems. The life of silica crowns has been reduced by more than $50 \%$ due to increased $\mathrm{NaOH}$ and $\mathrm{H}_{2} \mathrm{O}$ by a factor of 3 in oxy-fueled furnaces. Glass melting customers are requiring cleaner and higher quality glassmaking and total elimination of $\mathrm{NO}_{\mathrm{x}}$ emissions. This forces the refractories industry to develop better or alternative refractories.

In recent decades, the most revolutionary development in the refractories industry is probably the development of low and ultra low cement castables. These castables not only have comparative properties with fired bricks, but also provide ease of installation. Many of the time-consuming and costly brick making processes are eliminated in the production of castables and working environments are improved. Castable formulations have been developed for almost all applications and from all refractory minerals (such as magnesia based, high alumina, SiC, and mullite castables). Spinel-forming and spinel-reinforced low cement castables have become very popular, replacing chromium-containing and $\mathrm{MgO}-\mathrm{C}$ refractories in some cement kiln furnaces and in slag lines of steelmaking ladles, respectively. Monolithic refractories production has increased slightly during the past decade in Japan, whereas shaped refractories production has decreased significantly (Figure $2)$. 
Although refractories are made from very refractory minerals (periclase, lime, alumina, and spinel) and new and better refractory products have been developed (low cement spinel-based castables), they are, nonetheless, not perfect materials. These refractories are exposed to corrosive molten slags, which will be described in the next section, and gaseous chloride and alkalis at high temperatures. Corrosion of refractories becomes a very important factor when a new process technology or a new refractory product is introduced.

\section{Corrosive Factors and Refractory Interactions}

Slags are glassy or devitrified materials generated during metal refining and other ceramic, metallurgical, and combustion processes. They are derived from impurities in the molten metal or raw ores. They cover a wide range of composition depending on the specific melting and refining processes.

In almost all stages of steelmaking (blast furnace, BOF/EAF vessels, tundish, ladle, degasser and submerged entry nozzle) refractories make contact with slags of different chemistries. Submerged entry nozzle refractories $\left(\mathrm{Al}_{2} \mathrm{O}_{3}-\mathrm{C}, \mathrm{ZrO}_{2}-\mathrm{C}, \mathrm{Al}_{2} \mathrm{O}_{3}-\mathrm{ZrO}_{2}-\mathrm{SiC}-\mathrm{SiO}_{2}-\mathrm{C}\right.$ composites), for example, are subjected to fluorine containing mold fluxes at the metal line. The slag produced during the primary steel making stage in the BOF or EAF is known as "tap slag". Initially this tap or BOF slag has a $\mathrm{CaO} / \mathrm{SiO}_{2}$ ratio of about 1 , but the composition changes during the process (oxygen blowing) and it becomes more basic at the late stages of the $\mathrm{BOF}$ process. The $\mathrm{CaO} / \mathrm{SiO}_{2}$ ratio may reach 2 to 4 in the final stage. After tapping from the BOF (or EAF), the molten steel is transferred to the ladle for further refining. The slag, which is produced in ladle is called "raker slag" or ladle slag. The composition of the finished ladle slag becomes more basic, essentially composed of Ca-aluminate and spinel. Most steel plants utilize a more basic slag composition in recent years in ladles and degassers due to lesser $\mathrm{MnO}, \mathrm{FeO}\left(\mathrm{Fe}_{2} \mathrm{O}_{3}\right)$, and $\mathrm{Cr}_{2} \mathrm{O}_{3}$ in the slag for low carbon, Ti-toughened, $\mathrm{Al}$ killed steel. The composition of inclusions in steel has shifted from alumina to $\mathrm{Mg}$-aluminates and $\mathrm{Ca}$-aluminates. Oxidation of $\mathrm{Ti}$ in the metal in a vacuum degassing unit by magnesia-chrome results in failure of these refractories.

In other ceramic and chemical processes, such as in $\mathrm{TiCh}_{4}$ fluidized bed incinerators, refractories are subjected to very corrosive chlorine containing gaseous atmospheres. In phosphorous combustor plants, the refractories may experience wollastonite slag attack. These are only a few examples in which the failure of refractories is commonly experienced via corrosion.

Slag practices in copper production furnaces have traditionally been based on ferrous silicates or fayalite slags. Recent technological developments in copper converter practice have resulted in ferrite-type slag practices because Ca-ferrite slag practice improves the removal of undesirable impurity elements such as $\mathrm{Sb}, \mathrm{As}$, and $\mathrm{Bi}$ from the blister copper. Because the basicity of a ferritetype slag is increased, there is a concern that $\mathrm{Cr}^{6+}$ would also be promoted to significant amounts in slag as well as in the magnesia-chrome refractories used. The mineralogical study of magnesiachrome as well as spinel-based castable refractories, which are exposed to calcium ferrite type slag, becomes a vital interest to researchers. Traditional magnesia-chromite and newly developed spinelbased castable refractories, which are exposed to fayalite- and ferrite-type slags have already been thoroughly studied [6-9].

Lastly, the service life of silica crown bricks in oxy-fueled glass melting furnaces has been dramatically reduced by alkali vapor corrosion of silica bricks. Finding ways to reduce corrosion of 
glass plant refractories is very challenging. Postmortem analyses of salvaged conventional silica bricks from float and TV-panel glass production furnaces provide some insight into a better understanding of silica crown brick corrosion [10]. Characterization of newly developed crown refractories, which are alternative to conventional silica bricks, and improved silica bricks are current research interests in glassmaking industries [11]. Fusion cast alumina-zirconia-silica (AZS) refractories, which are the primary glass contact refractories, have also been used as a crown material in oxy-fueled fired TV-panel glass production furnaces. Fused cast $\beta$-alumina blocks have also been used for the crown of glass melting tanks as well. The corrosion of these materials has increased the stone defect formation, which is not tolerated in TV-panel glasses [12-13].

The purpose of this paper is to present several case studies in which refractories have been chemically corroded and to demonstrate the application of cathodoluminescence microscopy to such materials.

\section{METHODS OF ANALYSIS}

Refractories, reaction interfaces, and slag mineralogy have traditionally been studied by standard optical microscopy [14-17]. Although optical microscopy has been an essential technique in refractories research, rapid phase recognition and quantification by reflected light (RL) or transmitted light (TL) microscopy is very difficult. Reflectance and hardness of most insulating oxide and silicate minerals are very similar by reflected light microscopy. Associated techniques such as chemical analysis and x-ray diffraction (XRD) analysis are, therefore, often applied to assist in phase identification.

Scanning electron microscopy (SEM) and electron microprobe (EPMA) techniques are commonly used to study microstructures of refractories and their reaction interfaces. Although these techniques provide superior spatial resolution, they are expensive, time-consuming, and require many spot analyses and standards for phase identification due to similar or overlapping back scattered electron coefficient of many of the minerals in refractories and slags. This creates difficulty for rapid recognition of phases and phase distribution. EPMA analyses do, however, provide superior and precise data on chemical composition of the minerals of interest.

TEM has recently been successfully applied to characterizing bond microstructures of direct bonded magnesia-chromite refractories [18] as well as to corrosion studies of different aluminas in steel slags [19].

Cathodoluminescence microscopy (CLM) has been a standard technique for studying a great variety of geologic materials over the past 20 years [20-21]. Limited numbers of CLM studies have been published for reference in solving metallurgical problems [22-23]. Although great numbers of SEM-CL studies were published on semiconductor and phosphor ceramics [24-25], the application of CL to other ceramic materials, such as technical ceramics and refractories, has not been comprehensively realized.

The authors have been applying CLM to a variety of refractory shapes, refractory raw materials, and to post-mortem materials [26-28]. CLM, in conjunction with RLM and SEM provides 
immediate assessment of the distribution of identified phases. Identification is possible by CL itself, using CL colors, mineral habit and texture of the crystalline phases.

Almost all thermally processed refractory raw materials and reaction products cathodoluminesce brilliantly, displaying characteristic colors when bombarded by high-energy electrons. Although CL microscopy is comprehensive when applied to most refractories and slags, those phases high in $\mathrm{Fe}^{2+}$ will not yield sufficient CL information to allow full application of the method. The authors have compiled large amounts of CL data over the years for minerals found commonly in refractories and slags.

\section{Cathodoluminescence Technique}

CL microscopy utilizes a beam of electrons that interacts with the specimen surface. As a result of electron beam-specimen interaction refractory minerals and phases in specimens produce characteristic CL colors. Trace elements, lattice defects, or intrinsic properties within the crystal typically cause this emission of photons by minerals, known as cathodoluminescence. Activators, such as transition metal ions $\left(\mathrm{Mn}^{2+}, \mathrm{Cr}^{3+}, \mathrm{Fe}^{3+}\right)$ and rare earth activators $\left(\mathrm{Eu}^{2+}, \mathrm{Sm}^{3+}, \mathrm{Tb}^{3+}, \mathrm{Dy}^{3+}\right)$, can create luminescence if present in trace amounts. Cation and anion vacancies lattice defects can also cause CL. A few ions, such as $\mathrm{Fe}^{2+}$, quench the CL process.

Refractories raw materials are not completely pure minerals and contain trace amounts of impurities, which are carried over as contaminants in processed materials as well. Because refractories are thermally disturbed (processed) materials, they also contain higher concentration of lattice imperfections (defects). These impurities and defects are beneficial to effective CLM of refractory minerals and products.

\section{CLM APPLICATIONS AND CASE STUDIES}

\section{General Applications to Refractories}

The potential application of CL microscopy to refractory materials and products is very comprehensive because all thermally processed refractory materials and products cathodoluminesce spectacularly. CL microscopy may be applied to refractories and post-mortem materials to study:

- Rapid phase identification, quantification, and mapping of phase distribution

- Determination of wear and corrosion mechanisms of refractories

- Detection of foreign inclusions, impurities, and contaminants

- Internal sintering behavior of refractories

- Polymorphic transformation of phases

- Grain growth, zoning, and recrystallization

- Crystallization textures of slag upon cooling

- Tracing sources of defects in glass

- Inclusions in steel and other metals

\section{$\underline{\text { CLM Case Studies }}$}

$\underline{B O F}$ and Ladle Refractories and Slags. The unique applications of CLM for post- mortem MgO-C refractories from steel making plants have been well demonstrated [29-30] and are not discussed in 
detail here. The only technique effective for determining the distribution, forms and development of spinel and $\mathrm{AlN}_{\mathrm{ss}}$ phases from hot face to cold face of the brick was CLM. Spinel cathodoluminesced green and $\mathrm{AlN}_{\mathrm{ss}}$ cathodoluminesced red-orange, making distinction between these two phases possible by CLM.

Tundish Veneer and Coatings. Tundish linings, in general, include a backup safety lining and a high alumina castable working lining. The surface of this working lining is coated with magnesia-based gunning mixes to make descaling work easier after casting.

Two unused (Batch A and Batch B) and three used tundish refractory coatings were studied by CLM to determine mineralogical variation and correlate composition to performance. Unused samples are very similar in microstructure but differ in $\mathrm{Na}_{2} \mathrm{O} \cdot \mathrm{SiO}_{2}$ content. They are extremely porous and contain sintered $\mathrm{MgO}$ aggregates bonded with silicate phases. $\mathrm{MgO}$ aggregates exhibit dull brown-red CL in both samples. Silicate impurity phases within the $\mathrm{MgO}$ aggregates are bright yellow CL monticellite and bright pink-red CL forsterite identified by CL microscopy.

Post-mortem sample Batch A represents the material that lasted four heats. It includes a thick (approximately $25 \mathrm{~mm}$ ) top porous grey zone, and a thin (approximately 1-2 $\mathrm{mm}$ ) white transition zone, and a thin (approximately 1-2 mm) bottom dark zone. This thin dark zone is in contact with the alumina-based castable working lining. A calcium aluminate slag (liquid) layer containing $\mathrm{FeO}$ has developed between the $\mathrm{MgO}$-based tundish coating and the alumina castable working lining. The thin white transition zone is a dense spinel zone. Spinel crystals in this zone generally exhibit brilliant red CL, as well as bright green CL. Some crystals show alternating red CL and green CL internal zoning. Many of the spinel crystals also contain $\mathrm{Fe}-\mathrm{Cr}$ spheres at their centers and the red $\mathrm{CL}$ color is correlated to $\mathrm{Cr}^{3+}$ in the spinel structure. The grey zone forms a large portion of this tundish coating refractory, and the original porous microstructure is totally modified. Large amounts of liquid phase (monticellite and forsterite) have crystallized between sintered periclase in this zone, resulting in reduction of porosity (Figure 3).

Olivine-based tundish veneer materials were also studied by CL microscopy (Figure 3). CL microstructures have revealed that olivine $\left[(\mathrm{Fe}, \mathrm{Mg})_{2} \mathrm{SiO}_{4}\right]$ sands do not exhibit CL, but due to the recrystallization of olivine, one can clearly observe bright red CL crystals of forsterite. Because of interaction with the tundish cover, which are typically composed of high alumina castables, monticellite as well as spinel are also formed. In both examples, FeO reduction and spinel formation are characteristic of the processes.

Submerged Entry Nozzle. Submerged entry nozzles (SENs) are used to transfer molten steel from the tundish to the mold providing continuous flow of steel and preventing oxidation of steel. SEN refractories should, therefore, have high refractoriness, corrosion resistance to mold powder slag, and high thermal shock resistance.

Commercial SENs were originally made from fused silica, but presently alumina-graphite (A-G), zirconia-graphite (Z-G), zirconia-calcia-graphite (Z-C-G), alumina-zirconia-SiC-graphite, or other compositions containing graphite are used. The life of SENs are limited by two main factors: (1) nozzle clogging phenomenon in the inner bore of the SENs, and (2) corrosion of SENs in areas where SENs make contact with mold powder slag.

Cathodoluminescence microscopy has been applied for the first time to studying the clogging phenomena in continuous casting of low carbon, Al-killed steel [31]. CLM has provided better 
understanding of the mechanisms of nozzle clogging and nozzle corrosion. Clog and mold flux mineralogy was determined and sources traced by means of cathodoluminescence microscopy.

Figure 4 shows the corrosion of a typical clog in a Z-G SEN from stainless steel casting. In the literature, these build-up deposits are commonly described as alumina clog or alumina accretions. In this case, however, it is primarily a spinel deposit as determined by CLM.

The corrosion of SENs occurs not only at the mold powder slag line but also inside the nozzle bore or on the metal side. The characteristic zones developed in this particular post-mortem SEN are as follows (from inner bore or metal side to outer slag line):

- Frozen bulk steel

- A loosely held or powdery, or sponge-like spinel and alumina clog, approximately $5 \mathrm{~mm}$ thick (Figure 4A and 4B)

- A well sintered but porous Ca-aluminate layer (Figure 4C and 4D)

- A well sintered Ca-zirconate layer (Figure 4C and 4D)

- A 2-3 mm thick reaction zone where calcia-stabilized zirconia grains are reduced and zirconium carbide has formed on the surface of graphite flakes (Figure 4E and 4F)

- Unaltered Z-G body

- A slag penetration zone where molten mold slag has penetrated between zirconia grains, graphite flakes, and through pores resulting in the granulation of zirconia grains

- Attached crystallized mold slag (Figure 4E and 4F)

Each zone or layer has produced characteristic CL and microstructures as shown in Figure 4. The contrast between alumina (red CL) and spinel (green CL) in the powdery deposit is very clear (Figure 4B). The fluorine-containing slag penetration into SEN refractory and alteration of zirconia grains are best observed in CL images. Cuspidine, a fluorine-containing calcium silicate phase $\left[\mathrm{Ca}_{4} \mathrm{Si}_{2} \mathrm{O}_{7}(\mathrm{~F}, \mathrm{CO})_{2}\right]$, is the primary constituent of the mold slag and it exhibits brilliant orange-yellow CL color (Figure 4F). It has formed dendrites in the slag due to rapid cooling but in the penetrated zone, liquid (glassy or amorphous) phase of similar composition and CL characteristic to cuspidine is observed. It is this amorphous fluorine-containing calcium silicate phase (similar CL and composition with cuspidine) that causes alteration and granulation of zirconia grains. The zirconium carbide could only be formed in a non-reactive atmosphere, such as during argon injection.

Fluidized Bed Refractories from Titanium Chlorinating Plants. Typical feed material for $\mathrm{TiO}_{2}$ chlorinating processing may contain rutile ore, synthetic rutile, leucoxene, and ilmenite, as well as slag. In this process, oxide ores are reacted with chlorine in a fluidized bed containing petroleum coke. As a result, oxygen combines with the coke to form $\mathrm{CO}$ and $\mathrm{CO}_{2}$ while titanium and chlorine combine to form $\mathrm{TiCh}$. Typical operating temperature varies from $800^{\circ} \mathrm{C}$ to $1000^{\circ} \mathrm{C}$. Fireclay refractories are commonly used in the fluidization zone, while high alumina castable refractories are preferred in the burner.

In this case study, the corrosion of mullite-based bricks is described. The peculiar problem encountered in this operation was spalling and crumbling of these hard fireclay bricks occurred at the backside of the fluidized bed, rather than on the hot side. CL photomicrographs in Figure 5 feature distinct microstructures of such material, which could not be observed by other techniques. CLM clearly shows that reaction between chlorides and fireclay bricks resulted in the formation of aluminum chloride (Figure 5A and 5B). The alumina component of the brick selectively dissolved to form aluminum chloride and cristobalite. The former can easily hydrate to form aluminum chloride hydrate, a get like amorphous liquid that can leave the system yielding porous cristobalite. 
In this particular case, the feed stock material must have contained other impurities, such as $\mathrm{MnO}$, $\mathrm{FeO}, \mathrm{MgO}$, and phosphates (Figure 5C). These impurities can also easily react to form chloride phases.

The corrosion mechanism in this example is the reaction between $\mathrm{TiCh}_{4}$ and the aluminosilicate brick, resulting in precipitation of rutile and dissolution of mullite (Figure 5A, 5C, and 5F). CL micrographs reveal the corroded mullite relicts or islands in the porous cristobalite (Figure 5D and 4E).

Spinel Added and Spinel Forming Castable Monolithic Refractories. This group of monolithic refractories is very popular in Japan, and has now gained in popularity in the US for a wide variety of applications. There are basically two kinds of these monolithics: 1) spinel reinforced or spinel added castable, and 2) spinel forming castable. In the former type, fine spinel grains are added to the matrix formulation and in the latter one spinel is formed in situ during service as a result of reaction between magnesia and alumina. Both periclase ( $\mathrm{MgO})$ and alumina, as well as spinel grain, are used as aggregate and fine-grained fillers. Spinel forming magnesia castables are preferred in transition zones in cement production plants. Spinel added or spinel forming high alumina castables are commonly used in steel ladles. The case study illustrated in Figure 6 is a spinel forming high alumina castable after service. It is clear that a fully dense, well-sintered spinel ceramic bond has been formed in the hot face of the castable. The fillers and grains are highly impure. Defective fused brown alumina grains have a high content of $\mathrm{FeO}$ and $\mathrm{TiO}_{2}$ and, therefore, many of them exhibit CL colors (Figure 6B, 6D, and 6F). This example shows that the spinel based castable refractories are perfectly suited to study by the cathodoluminescence technique.

Laboratory Test Samples. Slag-cup test samples exposed to synthetic steel $\mathrm{CaO}-\mathrm{MgO}-\mathrm{Al}_{2} \mathrm{O}_{3}-\mathrm{SiO}_{2}$ (CMAS) slags can be best studied by CLM in order to determine the slag penetration and corrosion resistance of newly developed refractory test materials. The authors have studied the corrosion resistance and slag penetration of great numbers of refractories which have been exposed to various slag composition (unpublished data) over the course of several years. Two examples are demonstrated in Figure 7.

The first example illustrates a beautiful crystallization of forsterite and monticellite from top to bottom of the molten slag. At the bottom (lower portion of the slag in a $\mathrm{MgO}$ crucible) forsterite forms euhedral or chain-like skeletal crystals and exhibits brilliant red CL (Figure 7C and 7D). These forsterite crystals have crystallized early and have settled on the surface of $\mathrm{MgO}$ crucible due to higher density. Both forsterite and monticellite (bright yellow CL) form fiber-like crystals due to the rapid quenching of the slag (Figure 7A and 7B).

The second example demonstrates the corrosion of high alumina brick by a CMAS slag. Dissolution of mullite into a CMAS slag progresses by the formation of anorthite (yellow CL) and needle-like corundum (red CL) crystals on the surfaces of mullite aggregates (Figure 7E and 7F). Reaction between tabular alumina and CMAS slag resulted in the formation of a dense spinel layer on the surfaces of the alumina grains (not shown in Figure 7). The bulk slag cooled to form mostly amorphous glass, and large anorthite and euhedral spinel crystals. Anorthite crystals in the bulk of the slag interestingly exhibit intense blue CL color. This example shows that the CL technique is able to distinguish anorthite crystals crystallized in the bulk of the slag (blue CL) and anorthite crystals formed as a result of reaction between slag and mullite aggregates (yellow CL). 
Glass Plant Refractories and Glass Stone Defects. Corrosion of post-mortem glass contact AZS (fusion cast $\mathrm{Al}_{2} \mathrm{O}_{3}-\mathrm{ZrO}_{2}-\mathrm{SiO}_{2}$ ) refractories, and conventional silica crown bricks have been systematically studied by CLM $[10,13]$. They are excluded from this discussion. Corrosion of glass contact and crown refractories is, however, the main reason for formation of undesirable stones in glasses. Such stones have been studied by transmitted light microscopy and x-ray diffraction techniques in the past. Thin section specimen preparation and XRD study for such small stone in glass are, however, time consuming and problematic. CLM provides an excellent means to study these stones [12]. CLM also allows one to trace and pinpoint the sources of these stones. Figures $8 \mathrm{~A}$ and $8 \mathrm{~B}$ show alumina and AZS refractory stones observed in TV panel glasses, which cannot tolerate any stones. Both are derived from crown refractories. CLM often reveals partially preserved original microstructures of refractories used. In this case, AZS superstructure refractory is partially digested and alumina is selectively dissolved in the glass leaving undissolved zirconia grains. If a stone resides in a glass for a long time, the original microstructure is totally lost and it may recrystallize (Figure 8C and 8D). The recrystallized alumina stone in Figure 8D is observed in fiberglass, which resulted in the break down of the glass fibers. Other stones identified are yellow CL cassiterite (Figure 8E) and blue CL nepheline (Figure 8F). Each mineral constituent of the stone produces characteristic colors and morphology reflecting their history. The cassiterite stone in Figure $8 \mathrm{E}$ contains many small crystals of individual cassiterite crystals, which are believed to be derived from the tin electrode in the electric-melting glass making furnace. Nepheline exhibits a characteristic intense blue CL and is commonly observed in dendritic form.

\section{SUMMARY AND CONCLUSIONS}

CL microscopy, in conjunction with reflected light microscopy and SEM-EDS, yields a combined method approach for rapid recognition of the phases in all types of refractories and slags. The case studies described in this paper represent a small portion of the applications the authors have been studying over the past several years. The authors believe that CLM provides relevant information about phase identification, phase distribution, and corrosion of most all types of refractories.

\section{REFERENCES}

[1]Lee, W. E. and Moore, R. E., 1998, "Evolution of in Situ Refractories in the $20^{\text {th }}$ Century," Journal of American Ceramic Society, Vol. 81, No. 6, pp. 1385-1410.

[2]Lee, W. E. and Rainforth, W. M., 1994, Ceramic Microstructures: Property, Control by Processing. Chapman and Hall, London, UK.

[3]Refractories Handbook, The Technical Association of Refractories, Japan, 1998.

[4] Semler, C., 2000, U. S. Demand for Refractories to Reach \$2.8 Billion Through 2003, Ceramic Industry, Vol. 150, No. 9, pp.45-46.

[5]Seward, T. P., 1997, Some aspect of oxy-fuel glass melting, Glass Technology, Vol. 38, No. 5, pp. 150-151.

[6]Crites, M. D., Karakus, M., Schlesinger, M. E., Somerville, M. A., and Sun, S., 2000a, "Interaction of Chrome-Free Refractories with Copper Smelting and Converting Slags," Canadian Metallurgical Quarterly, Vol. 39, No. 2, pp. 129-134. 
[7]Crites, M. D., Karakus, M., Schlesinger, M. E., Somerville, M. A., and Sun, S., 2000b, "Refractory Interaction with Calcium Ferrite Slags," Interceram, Vol. 49, No. 2, pp. 88-91.

[8]Schlesinger, M. E., Karakus, M., Crites, M. D., Sommerville, M. A., and Sun, S., 1997, "Chrome-Free Refractories for Copper Production Furnaces," UNITECR'97, Proceedings of Unified International Technical Conference on Refractories, M. A. Stett, editor, American Ceramic Society, Westerville, pp. 1703-1709.

[9]Karakus, M., Smith, J. D., and Moore, R. E., 2000a, "Cathodoluminescence Mineralogy of Used MgO-C Bricks in Basic Oxygen Furnaces," Veitsch-Radex Rundschau, 1/2000, pp. 24-32.

[10]Wereszczak, A, Wang, H., Karakus, M., Curtis, W., Aume, V., and VerDow, D., 2000, "Postmortem Analyses of Salvaged Conventional Silica Bricks from Glass Production Furnaces," Glass Science and Technology (Glasstechnische Berichte), Vol. 73, No. 6, pp. 165-174.

[11] R. E. Moore, M. Velez, M. Karakus, W. L. Headrick, "Oxyfuel Firing Effects on Refractories," in Fundamentals of Refractory Technology, pp. 223-233, edited by J. P. Bennett and J. D. Smith, Ceramic Transactions, Vol. 125, The American Ceramic Society, Westerville, Ohio, 2001.

[12]Karakus, M. and Moore, R. E., 1998, "Seeking Solution to Glass Defects from Refractory Corrosion," The Glass Researcher, Bulletin of Glass Science and Engineering, Vol. 7, No. 2, pp. 13$14,17$.

[13]Karakus, M. and Moore, R. E., 1996b, " Post-Mortem Study of Glass Melting Furnace Refractories," Corrosion of Materials by Molten Glass, Ceramic Transactions, Vol. 78, G. A. Pecoraro, J. C. Marra, and J. T. Wenzel, eds., American Ceramic Society, Westerville, pp. 179-191.

[14]Warman, M. O., 1978, "The Role of Optical Microscopy in Refractories Development Within the Iron and Steel Industry," Journal of Microscopy, Vol. 114, No. 3, pp. 295-306.

[15]Treffner, W. F., 1965, "Petrographic Studies of Basic Oxygen Furnace Slags and Used Refractories," Ceramic Bulletin, Vol. 44, No. 7, pp. 546-554.

[16]Robinson, P. C., 1966, "Some Observation on Unused and Used Refractories from Oxygen Steelmaking Vessels," The Refractories Journal, pp. 218-222.

[17]Clark, C. B., 1966, "Reaction of Fused Cast Alumina Refractories with Metals and Slags," Journal of Metals, pp. 1047-1052.

[18]Goto, K. and Lee, W. E., 1995, "The "Direct Bond" in Magnesia Chromite and Magnesia Spinel Refractories," Journal of American Ceramic Society, Vol. 78, No. 7, pp. 1753-1760.

[19]Zhang, S., Rezaie, H. R., Sarpoolaky, H., and Lee, W. E., 2000, "Alumina Dissolution into Silicate Slag," Journal of American Ceramic Society, Vol. 83, No. 4, pp. 897-903.

[20]Marshall, D. J., 1988, Cathodoluminescence of Geological Materials, Unwin Hyman, 146p. 
[21]Barker, C. E. and Kopp, O. C. (editors), 1991, Luminescence Microscopy and Spectroscopy: Qualitative and Quantitative Applications, SEPM Short Course 25, 194p.

[22]Hagni, R. D., 1985, "Cathodoluminescence Microscopy Applied to Mineral Exploration and Beneficiation," Applied Mineralogy, Proceedings of the Second International Congress on Applied Mineralogy in the Minerals Industry, W. C. Park, D. M. Hausen, and R. D. Hagni, eds., AIME, pp. 41-66.

[23]Hagni, R. D., 1986, "Industrial Application of Cathodoluminescence Microscopy," Process Mineralogy VI, R. D. Hagni, editor, TMS-AIME, Warrendale, pp. 37-54.

[24]Yacobi, B. G. and Holt, D. B., Cathodoluminescence Microscopy of Inorganic Solids, Plenum Press, 292p.

[25]Ozawa, L., 1990, Cathodoluminescence: Theory and Applications, VCH Publ., 308p.

[26]Hagni, R. D. and Karakus, M., 1989, "Cathodoluminescence Microscopy: A Valuable Technique for Studying Ceramic Materials," MRS Bulletin, Vol. XIV, No. 11, pp. 54-59.

[27]Moore, R. E. and Karakus, M., 1994, "Cathodoluminescence Microscopy: A Technique Uniquely Suited to the Solution of Refractory Wear Problems," Proceeding of the International Ceramic Conference Austceram 94, C. C. Sorrell and A. J. Ruys, eds., pp. 925-940.

[28]Karakus. M. and Moore, R. E., 1998, "CLM-A New Technique for Refractories," Ceramic Bulletin, Vol. 77, No. 6, pp. 55-61.

[29]Karakus, M., 1996a, "Cathodoluminescence Microscopy for Characterization of Steelplant Refractories," Refractories Application, Technology Quarterly for the Refractories Industries of North and South America, Vol. 1, No. 2, pp. 8-9.

[30]Karakus, M., Crites, M. D., and Schlesinger, M. E., 2000b, "Cathodoluminescence microscopy characterization of chrome-free refractories for copper smelting and converting furnaces," Journal of Microscopy Vol. 200, No. 1, pp. 50-56.

[31]Karakus, M., 2000c, "Study of Submerged Entry Nozzles by Means of Cathodoluminescence Microscopy," in preparation for Journal of Microscopy. 

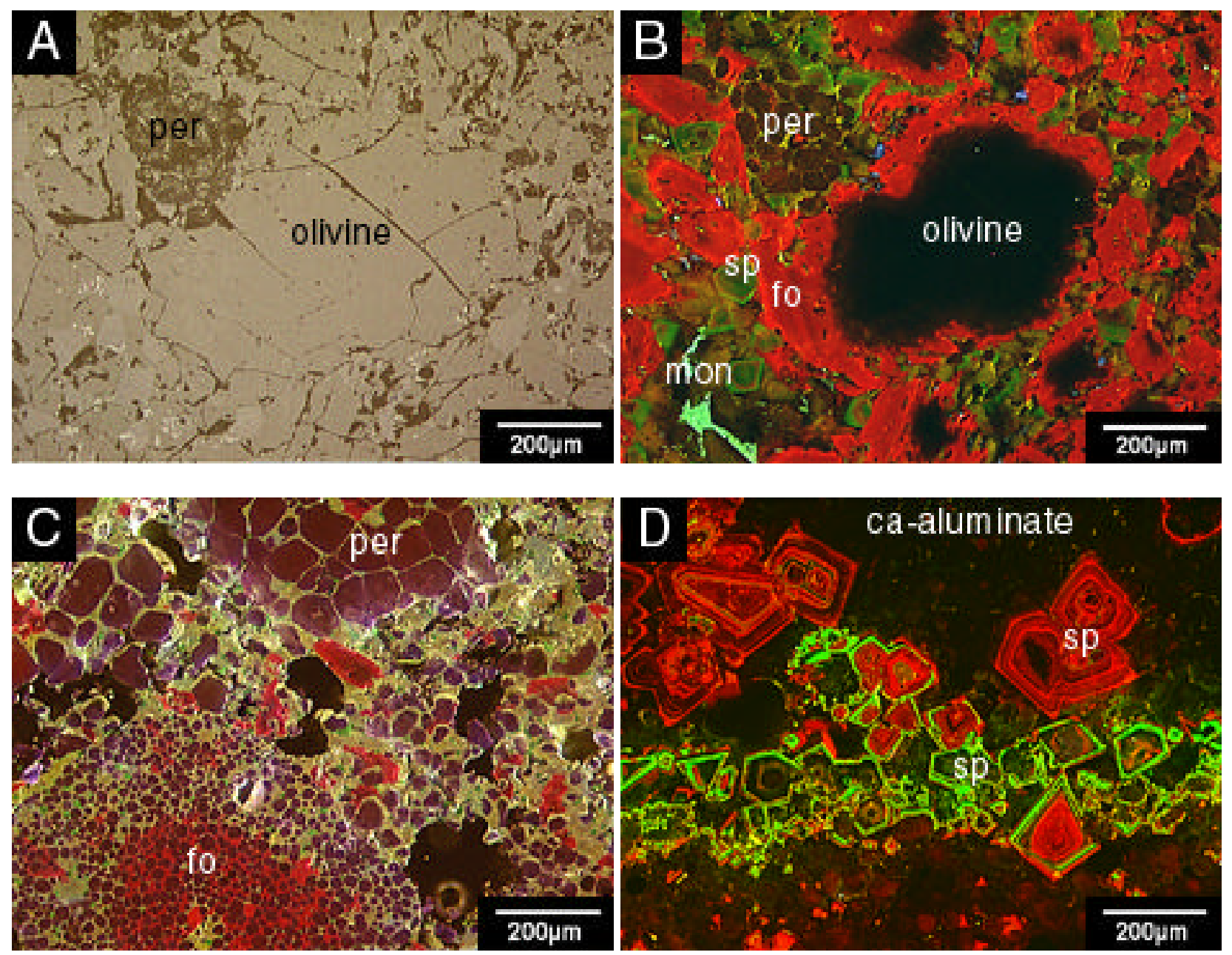

Figure 3. Tundish veneer and coatings. A-B) Reflected light (A) and cathodoluminescence (B) photomicrographs of olivine tundish veneer showing re-crystallization of non-CL olivine $\left[(\mathrm{Fe}, \mathrm{Mg})_{2} \mathrm{SiO}_{4}\right]$ to bright red CL forsterite (fo), zoned green-red CL spinel (sp), and dull pale yellow CL monticellite (mon), C) CL microstructure of $\mathrm{MgO}$-based tundish coating showing sintered periclase (per) and formation of large quantities of red CL forsterite (fo) and dull pale yellow CL monticellite, and D) CL microstructure of calcium aluminate slag (red CL) and spinel (green CL) layer on the surface of $\mathrm{MgO}$-based tundish coating. 

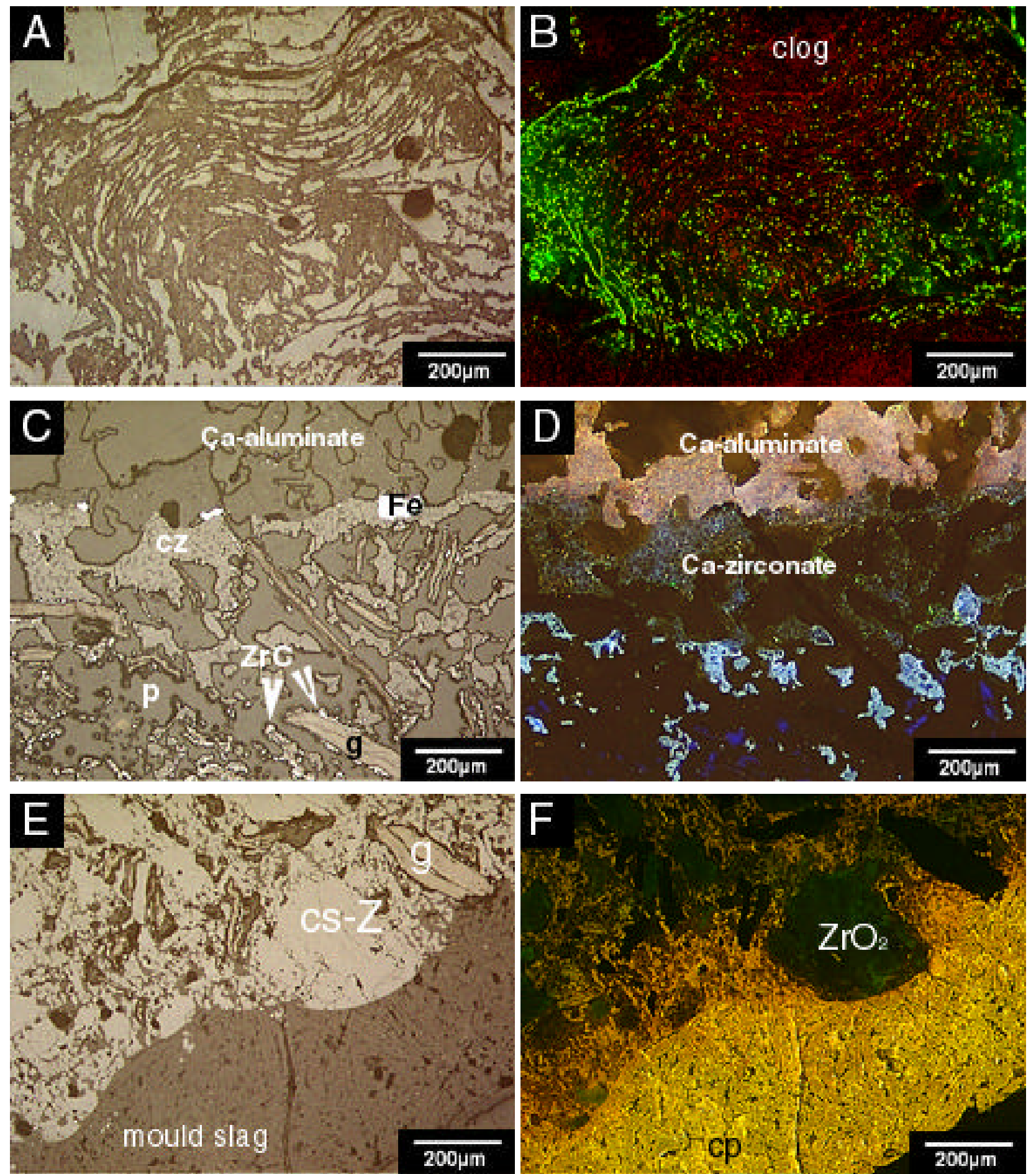

Figure 4. Post-mortem submerged entry nozzle (SEN) reflected light (A, C, and E) and cathodoluminescence (B, D, and F) photomicrographs. A-B) Powdery, loosely held spinel (green $\mathrm{CL}$ ) and alumina (red CL) deposits, C-D) altered refractory zone adjacent to clog showing a dense Ca-aluminate layer and $\mathrm{Ca}$-zirconate (cz) layer with metallic iron $(\mathrm{Fe}) . \mathrm{ZrC}$ are formed on the surface of graphite (g), and $\mathrm{E}-\mathrm{F}) \mathrm{ZrO}_{2}$-graphite nozzle corrosion by mold slag with pale yellow CL cuspidine (cp), fluorine-containing Ca-silicate mineral, and Ca-stabilized zirconia (cs-Z). 

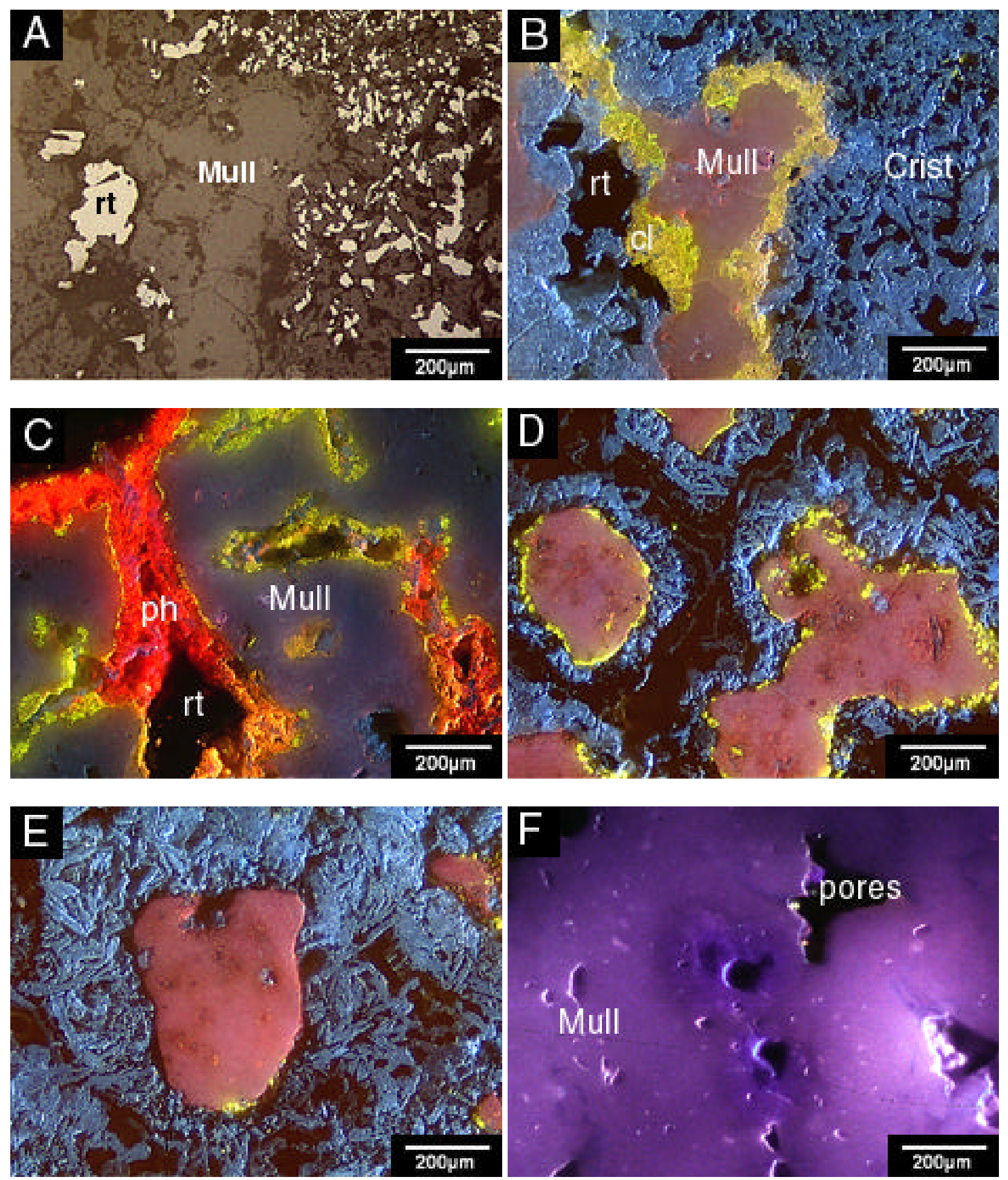

Figure 5. Titanium chlorinating plant mullite brick corrosion reflected light (A) and cathodoluminescence (B, C, D, E, and F) photomicrographs. A) Heavily corroded mullite (Mull) brick showing precipitation of rutile $(\mathrm{Ru}), \mathrm{B})$ corrosion of mullite by chloride phases and formation of porous cristobalite (Crist, blue CL) and Mn-Mg-chloride hydrate phases (cl, yellow CL) and precipitation of rutile (rt), C) corrosion of mullite brick by $\mathrm{Mg}$-phosphate (ph, red CL) and Mnchloride (yellow CL), and precipitation of rutile (rt, black), D and E) heavily corroded mullite brick showing disintegration of mullite islands by cristobalite, and F) relatively unaltered mullite brick. 

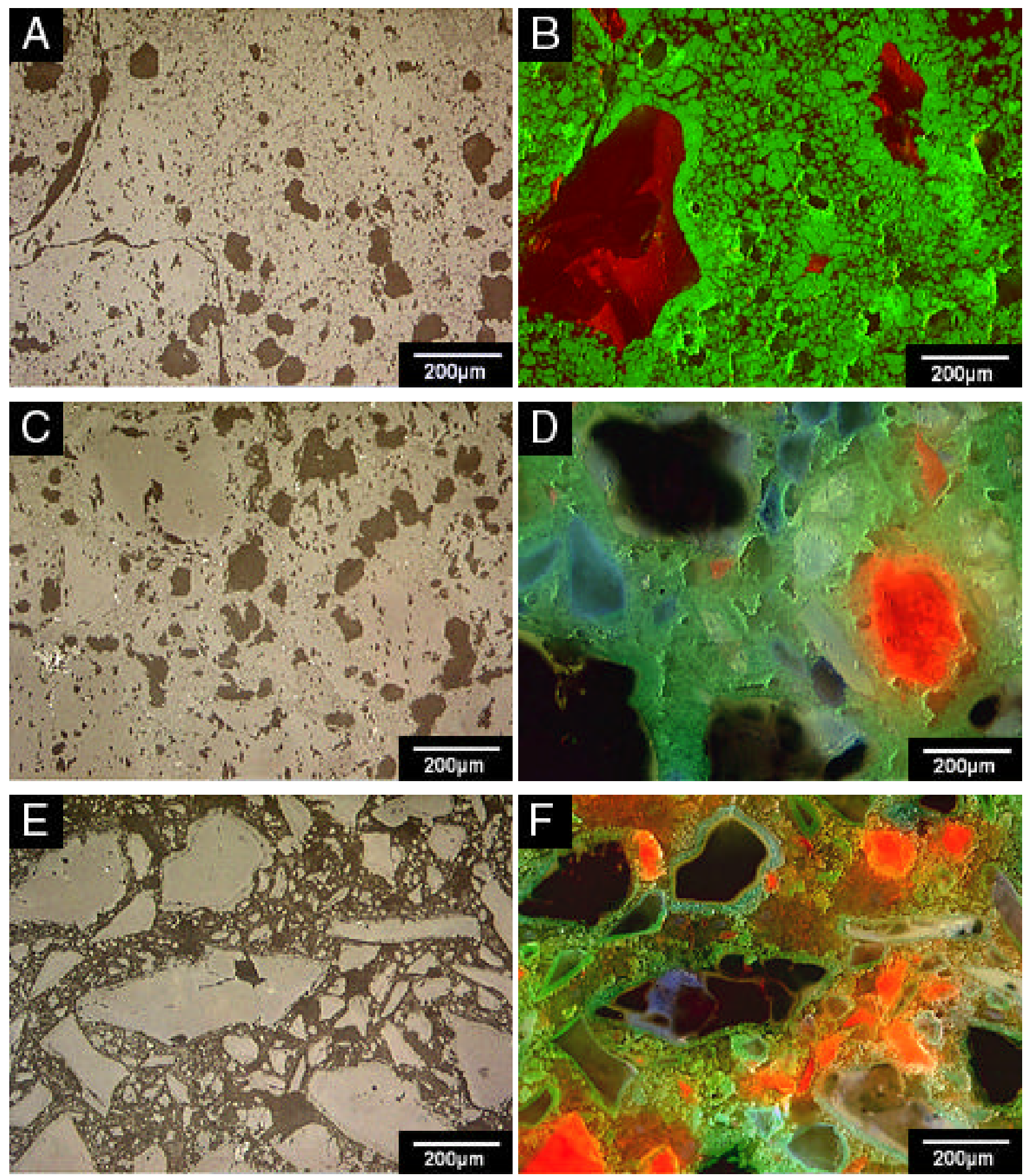

Figure 6. Spinel forming high alumina castable refractory after service reflected light (A, C, and E) and cathodoluminescence $(\mathrm{B}, \mathrm{D}$, and $\mathrm{E})$ photomicrographs show maturation of spinel ceramic bond. A-B) Hot face, C-D) center, and E-F) cold face and relatively unaffected zone with green CL spinel and dark red, blue and black and bright red CL fused brown alumina. 

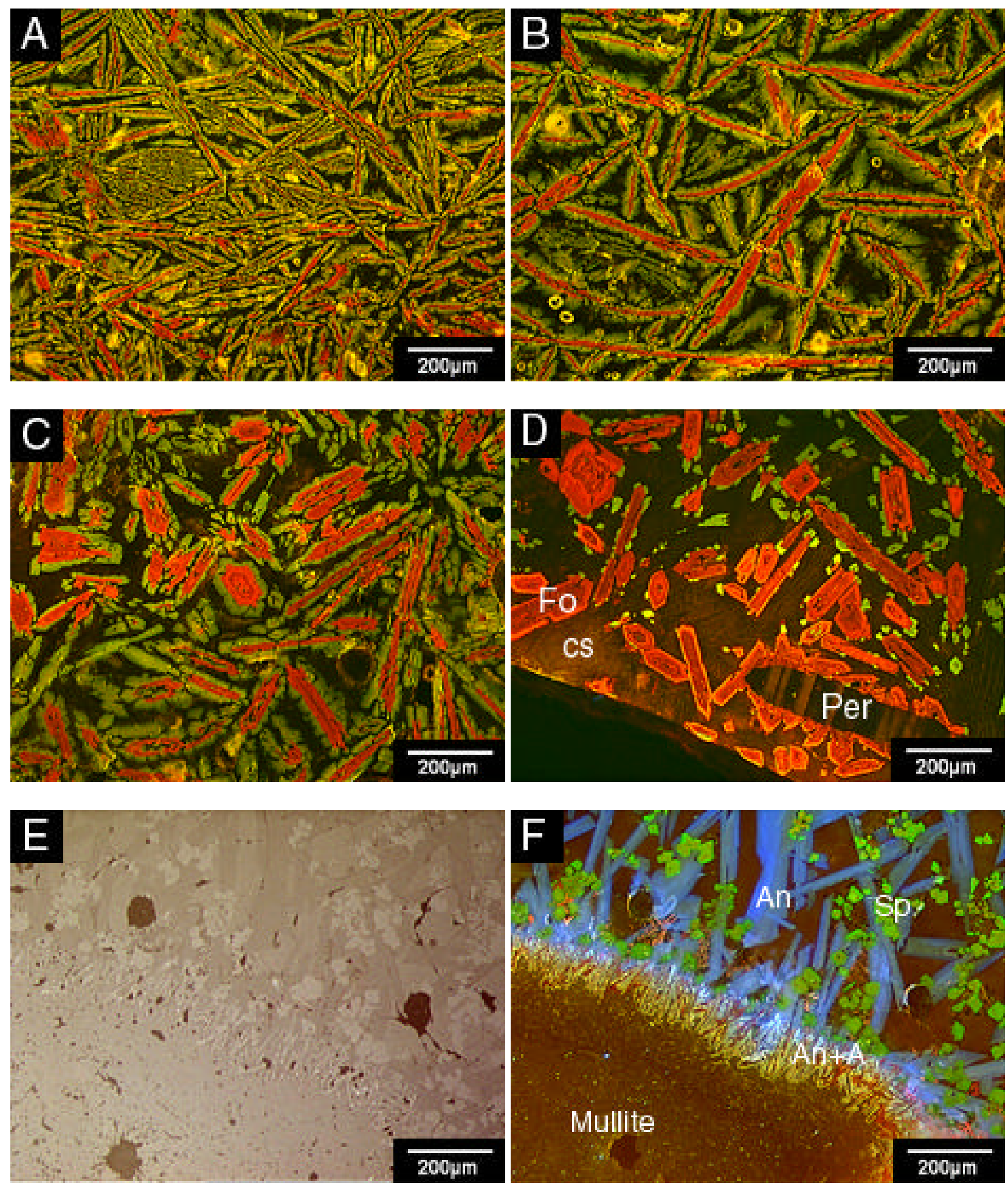

Figure 7. Synthetic $\mathrm{CaO}-\mathrm{MgO}-\mathrm{SiO}_{2}$ steel slag cathodoluminescence (A, B, C, D, and F) and reflected light (E) photomicrographs. A-D) Crystallization of monticellite (yellow CL) and forsterite (fo, red CL) from top (A) to bottom (D), rapid cooling produced fiber-like morphology at the top (A and B), crystals become more chain-like and euhedral morphology at the bottom (C and D), in a Casilicate (cs) matrix with fused periclase (Per) derived from the crucible, and E-F) mullite slag-cup test specimen showing corrosion of mullite by CMAS slag forming anorthite (An) and spinel (Sp) euhedral crystals. 

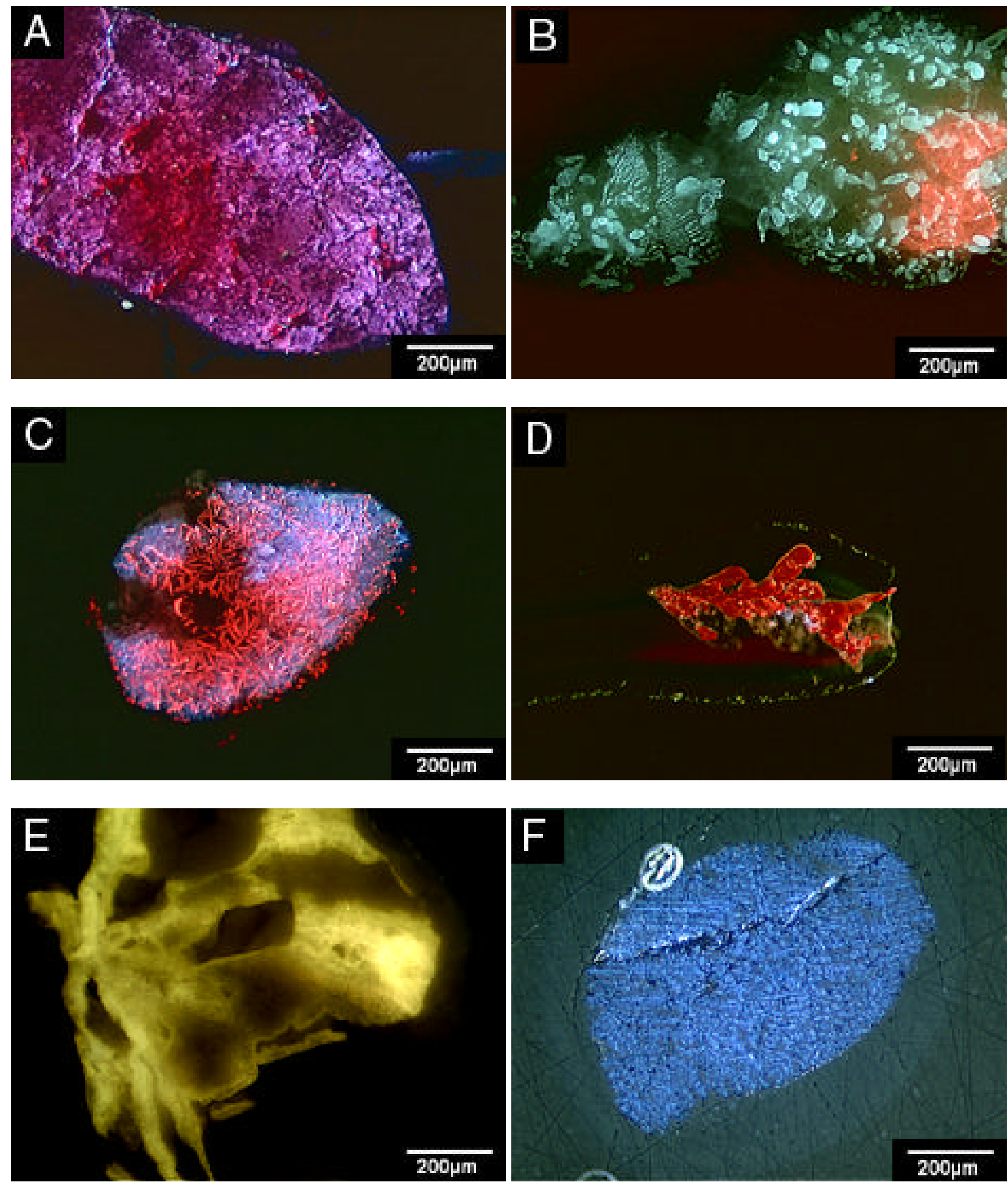

Figure 8. CL photomicrographs of glass stones (defects). A) Large alumina stone in TV panel glass, B) large and partially digested AZS stone in TV panel glass, C) alumina and nepheline clay stone in float glass, D) recrystallized alumina stone in fiber glass, E) cassiterite stone, and F) nepheline stone in TV panel glass. 